\title{
Cytotoxic Potential of Andrographolide against Bovine Tuberculosis
}

\author{
Ashish Shrivastava and H. K. Garg* \\ Research Scholar, Department of Biotechnology, CSA Govt. Post Graduate Nodal College Sehore - 466001 \\ (India) \\ *Professor of Cell \& Molecular Biology, Genetics and Biotechnology \\ Sarojini Naidu Govt. Girls Post Graduate (Autonomous) College,ShivajiNagar, Bhopal - 462016 (India)
}

\begin{abstract}
Bovine tuberculosis is a chronic mycobacterial infection that impinges on a wide range of mammals, including man, cattle, deer, pigs and carnivores. The present investigationdeals with the anti-mycobacterial potential of Andrographolide againstMycobacterium bovis, commonly known as bovine tuberculosis. The bioactive compound andrographolide was isolated from the leavesof Andrographis paniculata. Employing different techniques viz. zone of inhibition, disc diffusion and turbidometric method, the MIC of andrographolide was found to be vacillating between 100 and $11.11 \mu \mathrm{g} / \mathrm{ml}$ against the test organism (Garg\& Shrivastava, 2013). The results suggested andrographolide compound to be a potent antibiotic against M. bovis and its inhibitory effect is on par with standard drugs like isoniazid and fluoroquinolones.

Keywords: Andrographolide,Andrographispaniculata, Bovine tuberculosis, Mycobacterium bovis.
\end{abstract}

\section{Introduction}

Mycobacterium bovis is part of the Mycobacterium tuberculosis complex and is responsible for tuberculosis infections inseveral animal species, including human beings (Garnieret. al. 2003). Infection can occur through direct contact with an abrasion or by inhalation of contaminated air (Keller et. al., 2008). However, unpasteurized dairy products have been reported to be thelargest source of infectivity.

Thoughepisodes of mycobacterial contagion are not infrequent, yet our information, with reference torelative virulence of $M$. tuberculosis and $M$. bovis in man, post-infection possibilities, immunological consequences, occurrence of man-to-man transmission andits further spread to cattle,is still inadequate (Grange, 2001). Notwithstanding the fact that plants are potential source of chemical constituents with enormous propensity to synthesize a variety of structurally diverse bioactive compounds, very little documentation has been made regarding the cure of mycobacterial tuberculosis.

Andrographispaniculatais one of the plant resources containing bioactive compound - andrographolide and has been used in conventional Siddha and Ayurvedic system of meditation for multiple clinical applications since medieval times (Ahmed \&Aswami , 1993). The plant extract is known to exhibit anti-typhoid and antifungal activities. According to a study conducted at BastyrUniversity, Andrographispanuculata possessesantihepatotoxic, anti-biotic, anti-malarial, anti-hepatitic, anti-thrombogenic, anti-inflammatory, anti-pyretic and anti-snake venom properties (Najiv, 1999).

The present study is aimed to endorse 'andrographolide' as an effective bioactive compound and its therapeutic application in treatment of bovine tuberculosis.

\section{Plant extract}

\section{Material And Method:}

The leaves of A.paniculata were procured from nursery, dried in shade, \& subsequently in hot air oven, for 30 minutes at low temperature and then pulverized into dust or powder form. The dried powder wasthen used for extraction with solvent ethanol (Mishra et. al.,2011).

\section{Microorganisms}

The strain, M.bovis, used in the present study, was collected from MTCC IMTECH Chandigarh. M.boviswas sub-cultured and preserved in agar slants at $4^{\circ} \mathrm{C}$ for anti-mycobacterial study.

\section{Chemical analysis of Andrographolide}

Thin layer chromatography (TLC) analysis was carried out for the detection of andrographolide. Aprecoated plate of silica gel 60F254 (Merck) and mobile phase (chloroform : methanol : ethyl acetate - 8.0 : $1.5: 1.0)$ were used. The ethanolicextracts fractionated by TLC were detected through UV radiation (Electronic UV Trans-illuminator $: R f$ of andrographolide $=0.58)($ Suleet,et.al., 2010). 


\section{Screening for anti-mycobacterial activity}

The anti-mycobacterial activity of Andrographolide was scrutinized by using zone of inhibition, disc diffusion and turbidometric method. Isoniazid and fluroquinolones were taken as standard drugs for valid comparisons.

In zone of inhibition method, $6 \times 10^{4} \mathrm{CFU}$ of M.bovis was spread on Middle brook $7 \mathrm{H} 11$ agarmedia. Wells were dig on the plate with a hollow glass rod and were filled with equal concentrations of andrographolide, isoniazid \&fluroquinolones in $\log 2$ dilution. The experiment has a separate control for optimum growth of M.bovis. After 21 days, radius of inhibition was measured in $\mathrm{mm}$.

In disc diffusion method, sterile antibiotic discs (Himedia) were taken and filled up with 100, 33.33, 11.11, 3.77 and $1.23 \mu \mathrm{g} / \mathrm{ml}$ of andrographolide using micropipette. At the same time, safety measures were taken to protect the flow of the solvent extract from the outer surface of the disc. The discs were placed on the middle brook $7 \mathrm{H} 11$ agar plates on which the bacteria were inoculated, spread and incubated at $37^{\circ} \mathrm{C}$ for 21 days. The diameter of inhibition zone was measured in $\mathrm{mm}$.

In turbidometric method, $M$. bovis was added at the rate of $10^{8} \mathrm{CFU} / 2 \mathrm{ml}$ of $7 \mathrm{H} 9$ broth. Equal concentration of andrographolide, isoniazid and fluoroquinolones were added in $\log 2$ dilution. Again, the experiment has a separate control for optimal growth of M. bovis. After 21 days O.D. was taken at $600 \mathrm{~nm}$ in spectrophotometer. Inhibitory activity of andrographolidewas checked on the basis of optical density.

\section{Results:}

Each experiment was done five times and the mean values of percentage inhibition were presented (table - 1). The results obtained from ZOI, DDA and TM werecompared with standard antibiotics - isoniazid and fluroquinolones (Garg and Shrivastava, 2013). TM was found to be more effective assay for antibacterial study of M.bovisthan ZOI and DDM. The Andrographolide depicted the greatest inhibitory action $(98.0+0.42 \%)$ at $100 \mu \mathrm{g} / \mathrm{ml}$ concentration. The positive control for isoniazid and fluoroquinolones evinced $96.47 \pm 0.42 \%$ and $93.61 \pm 2.7 \%$ inhibition respectively at the same concentration.

Table-1: Growth inhibition of M. bovis by Andrographolide, Isoniazid and Fluoroquinolones

\begin{tabular}{llccc}
\hline Concentration $\boldsymbol{\mu g} / \mathbf{m l}$ & $\begin{array}{l}\text { Andrographolide } \\
\text { Mean } \pm \text { SD }\end{array}$ & $\begin{array}{l}\text { Isoniazid } \\
\text { Mean } \pm \text { SD }\end{array}$ & $\begin{array}{l}\text { Fluroquinolones } \\
\text { Mean } \pm \text { SD }\end{array}$ \\
\hline 100 & Zone of inhibition & $87.90 \pm 3.70$ & $94.50 \pm 2.70$ & $75.20 \pm 3.90$ \\
& Disc diffusion method & $93.14 \pm 3.10$ & $95.00 \pm 1.12$ & $93.60 \pm 2.70$ \\
& Turbidometric method & $98.00 \pm 0.42$ & $96.47 \pm 2.40$ & $93.61 \pm 2.70$ \\
\multirow{2}{*}{33.33} & Zone of inhibition & $71.90 \pm 4.30$ & $50.80 \pm 2.30$ & $47.90 \pm 1.20$ \\
& Disc diffusion method & $83.24 \pm 6.40$ & $42.30 \pm 1.40$ & $42.30 \pm 2.00$ \\
& Turbidometric method & $93.80 \pm 0.95$ & $92.50 \pm 0.30$ & $42.30 \pm 2.10$ \\
\hline \multirow{2}{*}{3.11} & Zone of inhibition & $57.30 \pm 6.00$ & $24.40 \pm 1.15$ & $46.10 \pm 1.14$ \\
& Disc diffusion method & $41.84 \pm 0.91$ & $37.10 \pm 1.79$ & $40.90 \pm 3.20$ \\
& Turbidometric method & $92.70 \pm 0.40$ & $90.89 \pm 3.60$ & $40.60 \pm 3.21$ \\
\hline \multirow{2}{*}{1.23} & Zone of inhibition & $24.80 \pm 2.40$ & $16.40 \pm 0.10$ & $29.60 \pm 5.20$ \\
& Disc diffusion method & $37.12 \pm 1.70$ & $26.30 \pm 8.00$ & $33.86 \pm 7.50$ \\
& Turbidometric method & $82.90 \pm 0.54$ & $82.69 \pm 0.87$ & $33.90 \pm 7.50$ \\
& Zone of inhibition & $17.80 \pm 2.80$ & $13.60 \pm 0.93$ & $09.40 \pm 2.50$ \\
& Disc diffusion method & $26.90 \pm 1.90$ & $21.60 \pm 2.70$ & $22.00 \pm 1.17$ \\
\hline & Turbidometric method & $55.10 \pm 5.00$ & $78.39 \pm 3.97$ & $22.10 \pm 1.14$ \\
\hline
\end{tabular}

Value are mean of $\%$ inhibition with $\pm S D(n=5)$ 
Figure- 1: Growth inhibition of M. bovis by Disc diffusion and Zone of inhibition.

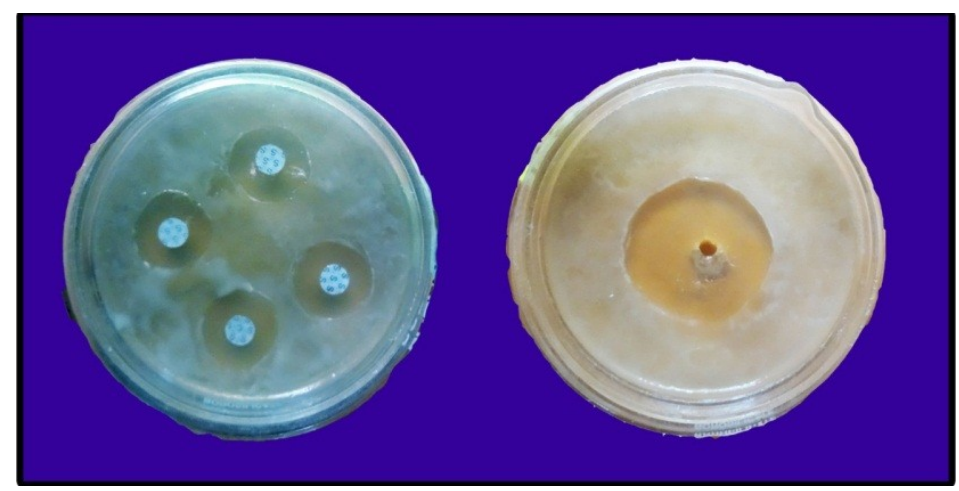

Figure- 2: Different concentration of Andrographolide, Fluoroquinolones and Isoniazid in M. bovis culture.

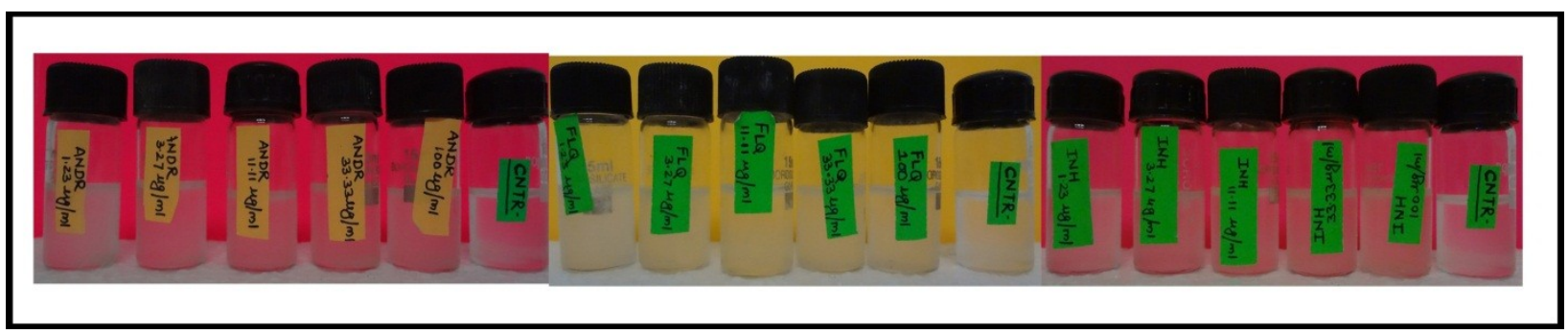

Figure- 3 : Growth inhibition of M. bovisby Andrographolide, Isoniazid and Fluoroquinolones.

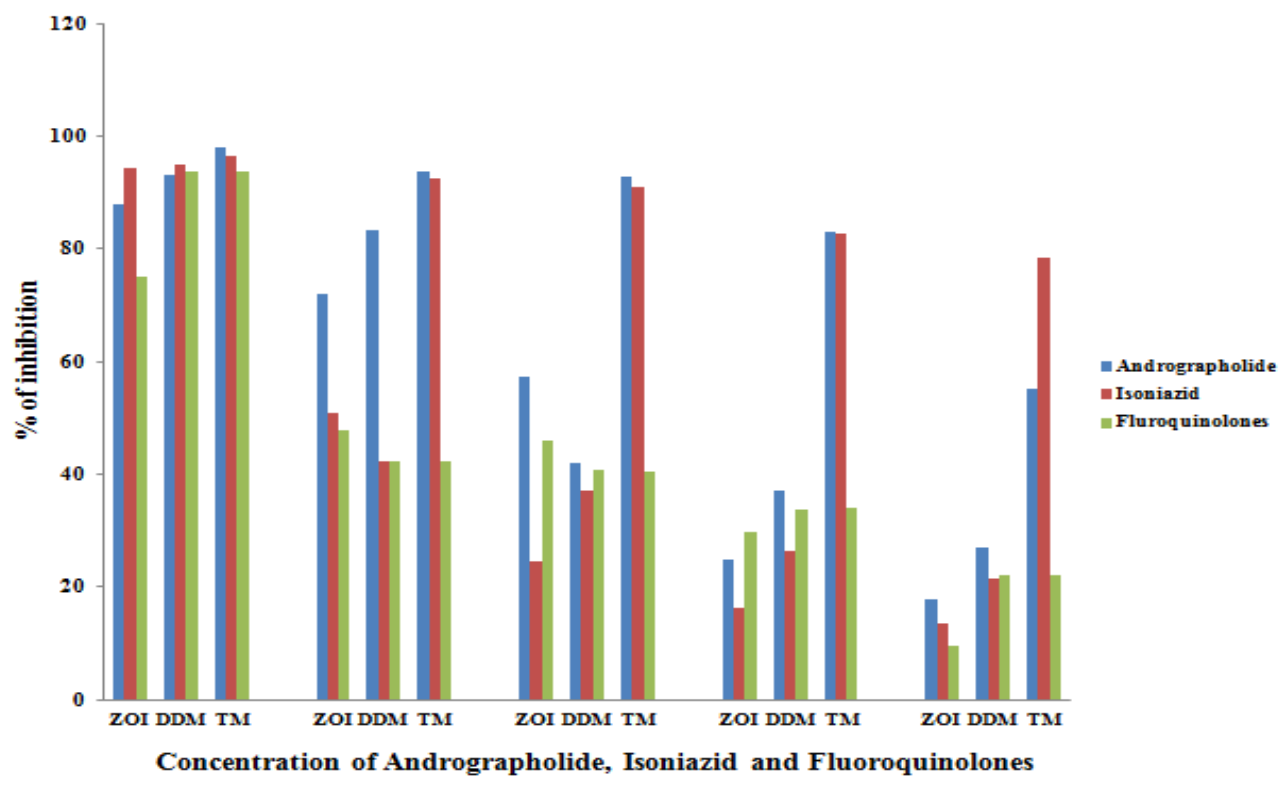

\section{Discussion}

The use of natural products as therapeutic agents has become ever more popular.However, only few plant species have been methodically investigated for their medicine properties.Gautamet. al.(2007) reported the plant families of Asteraceae, Lamiaceae, Fabaceae and Apiaceae has anti-mycobacterial activity . Gupta et. al.(2008)found theextracts of A. indica, A.vasica A. cepa A. sativumand A. verato exhibit anti-tuberculosis activity in L-J medium. Antony \& James (2011) reported the extracts of Alstoniascholaristo have $73.09 \%$ inhibition against clinical strain, resistant to streptomycin, isoniazid, rifampicin and pyrazinamide. The increasing incidences of MDR and XDR-TB worldwide have prompted the urgent need to look for novel antituberculosis drugs. In this wake, andrographolide flares up a hope against the nuisance activities of different strains of M.tuberculosis. 


\section{References}

[1]. Ahmed M. and Asmawi M.Z.(1993).Some pharmacological effects of aqueous of Andrographispaniculata Nees.International Conference on the Use of Traditional Medicines and Other Natural Product in Health Care (Abstract). University Sains Malaysia, Malaysia, 122

[2]. Antony M. and James J.(2012) .Anti-mycobacterial activity of plant Alstoniascholaris. Int. J. Curr. Pharm. Res., 4(1): 40-42.

[3]. GargH.K. and Shrivastava A. (2013). Clinical use of andrographolide as a potential drug against vole tuberculosis, J. Pure Appl. Zool.1(3) 223-226.

[4]. Garnier T. and Eiglmeier K. (2003). The complete genome sequence of Mycobacterium bovis. Proc. Nat. Acad. Sci. USA 100:7877-7882.

[5]. Gautam R. and Saklani A. (2007). Indian medicinal plants as a source of anti-mycobacterial agents. Journal of Ethnopharmacology, 110: 200-234

[6]. Grange J.M. (2001).Mycobacterium bovis infection in human beings. Pub Med. J., 81: 71-72.

[7]. Gupta R., Thakur B., Singh P., Singh H.B., Sharma V.D., Katoch V.M. and Chauhan S.V.S.(2008).Anti-tuberculosis activity of selected medicinal plants against multi-drug resistance Mycobacterium tuberculosis isolates. Ind. J. Med. Res., 131:809-813.

[8]. Keller P.M. andBottgerE.C. (2008). Tuberculosis vaccine strain Mycobacterium bovis BCG Russia is a natural rec-A mutant. BMC Microbiol.,8:120.

[9]. Misra C.S., Pratyush K., Sagadevan L.D.M., James J., Veettil A.K.T. and Thankamani V.(2011).A Comparative study on phytochemical screening and antibacterial activity of roots of Alstoniascholaris with the roots, leaves and stem bark,58: 124-131

[10]. Najib, N.A., Rahman, N.,Furuta, T., Kojima, S., Takane, K. and Ali, M.M. (1999)Anti malarial activity of extracts of Malaysian medicinal plants J. Ethnopharmacol. 64: 249-254.

[11]. Sule A., Ahmed Q.U., Samah O.A. and Omar M.N. (2010). Screening for antibacterial activity of Andrographis paniculata used in Malaysian Folkloric Medicine: A possible alternative for the treatment of skin infections, Ethnobotanical Leaflets, $14: 445-56$. 